\title{
Starting from the Same Spot: Exploring Mindfulness Meditation and Student Transitions in the Introductory Health Promotion Classroom
}

Madison MacQuarrie

Dalhousie University

Nicole Blinn

Dalhousie University

Samantha MacLellan

Dalhousie University

Megan Flynn

Dalhousie University

Jessie Meisner

Dalhousie University

Phoebe Owen

Dalhousie University

Becky Spencer

Dalhousie University 


\begin{abstract}
The purpose of this research was to explore student perceptions of mindfulness meditation (MM) in an introductory health promotion course, and how the use of MM during class might relate to the transitions experienced by students. Qualitative data collection took place through an online survey and in-person interviews. Data were analyzed using thematic analysis. Four key themes were identified from this research. First, that MM facilitates a sense of peace and calm; second, that MM encourages students to focus; third, MM helps promote student mental health; and finally, MM positively changes the classroom environment. Challenges and recommendations were also described.

Keywords: mindfulness, meditation, university, transitions
\end{abstract}

\title{
Résumé
}

Cette recherche avait pour objectif d'explorer la perception des étudiants de la «méditation de pleine conscience » (MPC) dans un cours d'introduction à la promotion de la santé, et en quoi l'utilisation de la MPC en classe peut être liée aux transitions vécues par les étudiants. La collecte des données qualitatives a été réalisée par le moyen d'un sondage en ligne et d'entrevues en personne. Une analyse thématique a permis d'analyser les données recueillies. Cette recherche a permis d'identifier quatre thèmes principaux. Premièrement, la MPC favorise un sentiment de paix et de calme ; deuxièmement, elle encourage la concentration des étudiants ; troisièmement, elle aide à promouvoir leur santé mentale ; et enfin, elle modifie positivement le climat de la classe. Finalement, des défis sont décrits et des recommandations formulées.

Mots-clés : pleine conscience, méditation, université, transitions 


\section{Introduction}

Beginning post-secondary education is a complex process of transition for students, especially the transition from high school to university (De Clerq et al., 2018; Christie et al., 2016; McInnis, 2010). This dynamic transition may require navigating change, instability, and shifts in identity and setting, which are intensified in the context of education (Coertjens et al., 2017; Hussey \& Smith, 2010; Gale \& Parker, 2014; Leese, 2010). Students are faced with various social, academic, personal, and institutional changes during their transition to university, and may experience feelings of anxiety or uncertainty associated with the adjustment (Christie et al., 2016; De Clerq et al., 2018; Gibson et al., 2018; Laing et al., 2005; Meehan \& Howells, 2018). The transition to university can be particularly challenging for first-generation students and other underrepresented populations in higher learning. These populations may not have the same social or cultural capital to feel a sense of belonging, or may not receive, or feel empowered to access, institutional supports and resources (Briggs et al., 2012; Coertjens et al., 2017; Leese, 2010; Meehan \& Howells, 2018).

Specific to the educational context, changes in academic expectations, ways of knowing, and approaches to learning may disrupt the development of a learner's identity and provoke feelings of anxiety and uncertainty (Coertjens et al., 2017; Hussey \& Smith, 2010). Low confidence, dropouts, and academic difficulties are common during the first year of university, indicating a critical time for student support during this transitional period (Coertjens et al., 2017; van Herpen et al., 2019; McGhie, 2017; Stone, 2010). Sometimes transition supports are provided, particularly to students with unique needs or disabilities, in the form of accommodative services, though evidence indicates current supports are generally insufficient; more research and revised policy and practices for supporting student transitions are needed (Coertjens et al., 2017; Janiga \& Costenbader, 2002).

Creating a supportive university learning climate can help students navigate the various transitions associated with undertaking higher education, contributing to student retention and success (Coertjens et al., 2017; Gibson et al., 2018; van Herpen et al., 2019; McInnis, 2010; Meehan \& Howells, 2018; Hussey \& Smith, 2010). Students in higher education may experience high levels of stress due to balancing academic workloads and other responsibilities (Kinsella et al., 2018; McConville et al., 2017; Schwind et al., 
2017). Given that stress and anxiety associated with the transition to university can result in negative experiences, higher education should consider going beyond teaching cognitive skills to include developing the tools for emotional well-being (Crowley \& Munk, 2017).

Meditation is predominantly used to provide techniques for facilitating focus. Mindfulness meditation (MM) more specifically focuses on paying non-judgemental attention to the present moment (Wisner et al., 2010). MM is a practice that embodies non-judgemental, self-compassionate awareness of one's own thoughts and sensations in the mind and body (Hick \& Bien, 2008; Shapiro et al., 2008). Though it is rooted in eastern Buddhist traditions and sometimes connected to religion or spirituality, MM need not be, and can be practised secularly as well (Wisner et al., 2010). MM has been shown to improve confidence and emotional regulation in both young people and adults and is often used as a therapeutic intervention (Jha et al., 2007; Monshat et al., 2012). Benefits of MM have been found to include decreased anxiety, stress, and depression; enhanced resiliency, attention, preparedness, and information processing; and improved creativity, empathy, and compassion (Bloch et al. 2017; Jha et al., 2007; Kabat-Zinn et al., 1992; Miller et al., 1995; Shapiro et al., 2008; Valentine \& Sweet, 1999).

MM has been incorporated into educational environments. Early use of MM in education predominately occurred with younger students, particularly those identified as underserved, vulnerable, or having mental health-related diagnoses (Waters et al., 2015). Recently, MM has been increasingly employed in higher education, with practices ranging from brief meditations at the beginning of a class to MM being fully integrated as a core part of the curriculum (McConville et al., 2017). Benefits of MM in the classroom include decreased stress, anxiety, and depression; and improved attention, self-efficacy, and empathy (Kinsella et al., 2018; McConville et al., 2017; Schwind et al., 2017). Further, a review on school-based meditation noted MM was also associated with decreased blood pressure and improved social skills, academic performance, and behavioural and emotional functioning (Wisner et al., 2010). Additionally, benefits of using MM may extend beyond students to also benefit the instructor and the overall learning environment (Schwind et al., 2017).

While MM is increasingly being used in education, its use in post-secondary educational settings warrants further rigorous study (Gardner \& Grose, 2015; Napora, 2011; Shapiro et al., 2008; Wisner et al., 2010). While research exploring the use of MM in 
post-secondary education indicates its promise, particularly in health-related disciplines (Crowley \& Munk, 2017; McConville et al., 2017; Rizer et al., 2016), there is a gap in the evidence associated with how MM may relate to student transitions.

Our introductory health promotion course offers a unique setting in which to explore MM in the context of post-secondary transitions, as many students in the course are transitioning from high school or other programs. MM was used in this course through a brief guided meditation led by the instructor at the beginning of each class. The meditations lasted between two and six minutes and focused on a variety of meditation techniques such as breath, sound, imagery, muscle relaxation, journalling, anchoring, and mindful eating. The purpose of this research was to explore student perceptions of using MM in the introductory health promotion course, and how the use of MM might relate to the transitions experienced by students in the BSc Health Promotion program.

\section{Methods}

\section{Study Design}

This study was designed and conducted from a post-structural paradigm, in which the instructor acknowledged her part in the dynamic experiences of students. Post-structural perspectives focus on analyses of texts and interrogation of meaning, language, and subjectivity (Cheek, 1999). Post-structural perspectives challenge the belief that language is neutral and interrogate language in the context and social reality it seeks to represent (Cheek, 1999). The research team acknowledged the social, political, and historical discourses associated with "higher learning"; other researchers have highlighted challenges of incorporating MM into the post-secondary classroom, noting it as beyond traditional ways of teaching and learning, and challenging common classroom power dynamics (Gardner \& Grose, 2015). Discourse surrounding the transition to university involves the idea that students are responsible for their own learning and resilience; however, research indicates student-centred pedagogy, social support from academic staff and students, and other institutional supports may facilitate student transition experiences (Briggs et al., 2012; Christie et al., 2016; Gale \& Parker, 2014; Gibson et al., 2018; van Herpen et al., 
2019; Hussey \& Smith, 2010; McInnis, 2010). As such, this study employed a participatory approach, with students as members of the research team.

The study was led by the course instructor with guidance and assistance from another faculty member in the School of Health and Human Performance at Dalhousie University in Halifax, NS, Canada. The teaching assistant for HPRO 1195 in Fall 2017 and 2018 coordinated the project, and student researchers contributed to each phase of the project, including study design, ethics and funding applications, data collection and analysis, and knowledge translation. Their individual engagement varied based on their interest, availability, and experience across all aspects of the project. Leadership, guidance, instruction, and resources were provided to the student researchers by more senior members of the research team.

\section{Data Collection}

Prior to data collection, ethical approval was granted by Dalhousie University's Research Ethics Board. Two forms of data collection took place: (1) an online survey, and (2) in-person interviews. The online qualitative survey included open-ended questions exploring experiences with MM and transitions, and was offered anonymously through Opinio, a secure online survey platform. Additionally, five individual interviews and one small group interview were conducted in person. Interviews were audio-recorded and lasted approximately 20 to 60 minutes. Survey and interview questions were developed collaboratively by the student researchers and approved by the rest of the research team. Survey and interview questions focused on how MM impacted students' experiences in the health promotion introductory course and how their experiences with MM impacted transitions they were experiencing during this time.

\section{Participants}

Participation in this study was open to students who took the introductory health promotion course in the Fall 2017 or Fall 2018 semesters at Dalhousie University. Typical enrolment for the course is around 40 students. Students who were part of the research team were ineligible to participate in the interview portion of data collection. Recruitment took place through emailing students and posting announcements on Brightspace, the 
online learning platform used for the course. In total, 25 online surveys were completed, and eight students were interviewed in person.

\section{Data Analysis}

Analysis involved an iterative process of reading and coding until themes were developed, guided by Braun and Clarke's (2006) process for conducting thematic analysis and Miles and Huberman's (1994) early steps in analysis. Online responses were compiled and imported into Microsoft Excel for management and organization. Interviews were transcribed verbatim by student researchers. Once transcription was complete, five student researchers met with the teaching assistant and instructor to create a plan for data analysis. Thematic analysis was selected due to its flexible nature and ability to assist development of a rich and detailed description of the data (Braun \& Clarke, 2006). The group separately coded the same interviews then met to discuss and compare potential codes and their definitions, as well as to identify patterns and themes from the data. A code book was developed and modified iteratively throughout the coding process. After the code book was drafted, the team of student researchers and the teaching assistant broke into pairs. Each pair was assigned a selection of interviews or survey responses to code separately, and then compared and discussed coding results with each other. The team then met to draft and compile themes collectively. The themes were then analyzed in light of existing knowledge and literature surrounding use of MM in the post-secondary classroom.

\section{Results}

Overall, participants expressed positive experiences using MM in the health promotion classroom. Participants began by discussing the use of MM in the course generally, saying they appreciated "the consistency and structure that the meditation practice had for our class," and how they found it to be "innovative" and "different from other classes." They also connected to the transitions they were experiencing by saying it "helped with these transitions as it gave me time to stop and reflect on my life choices and the new experiences." Participants connected MM directly to the course and its content, saying, with "such a small class where we kind of all were connected on a personal level I found 
that that made a huge difference for me," and "it also helped with kind of my view of health promotion...looking at it more holistically, I think it comes a lot from kind of this sort of practice." Many participants discussed how they now, "meditate every day," or "started using meditation outside of the classroom and it has had a large impact on my life and studies," describing the incorporation of MM beyond the classroom as well.

Through this work, four themes were identified: first, that MM facilitates a sense of peace and calm in the classroom; second, that MM encourages student focus; third, that MM promotes student mental health; and fourth, that MM positively changes the classroom environment. Finally, the participants discussed challenges and recommendations for the future. Each of these themes is discussed and supported with participant quotations below.

\section{Theme 1: MM Facilitates a Sense of Peace and Calm}

The most common feedback received regarding the incorporation of $\mathrm{MM}$ in the course was the sense of peace and calm it brought to the classroom. Many participants noted how they "felt calm and at peace before the lecture because of meditation." One student said, "Most people benefit psychologically from a few moments of sitting still quietly... just pausing... can have a surprisingly reassuring and calming effect.” Another summarized by saying MM "really helps clear your mind, calm your body and open your mind to study... I looked forward to this experience in this class every morning." Another noted the value of MM promoting a sense of calm before a test, saying, "The most significant thing I noticed was the impact of the meditation prior to tests and exams. I would arrive feeling rushed and crazy, and after the meditation, would feel calm, prepared and capable." Other participants connected the sense of peace and calm directly to the transitions they were experiencing at the time, with one saying that MM "could be helpful during transitions to help people be calm and focused on what they need to get done." Another said they found MM "to be calming which helped with my transition into health promotion. I found it helped relieve stress which helped with my challenges and worries," noting the meditations helped ease their transition to a new program of study.

Related to the feelings of peace and calm was the sense of pausing or slowing down. Many participants referred to the meditations as an opportunity "to pause for a few minutes" or "slow down a little bit," particularly when students were "feeling 
overwhelmed." One participant said, "We are often racing from one moment to the next, and the meditation practice at the beginning of class allowed a moment to stop and reset." Similarly, a participant summarized the collective moment together, saying, "Everyone slows down together, and then is able to begin together. I've heard collective mindful moments referred to as 'speed bumps' - a prompt to just slow down for a moment and become a little more aware of your surroundings before proceeding." One participant connected the idea of slowing down to the transition she was experiencing from the workforce back into post-secondary education, and the associated challenges in balancing various demands, saying, "I feel the meditation practice allowed me to pause, which was something I felt I wasn't giving myself permission to do," illustrating the impact of a moment to slow down collectively.

\section{Theme 2: MM Encourages Student Focus}

In addition to promoting a sense of peace and calm, participants also frequently discussed how MM encouraged them to be present, grounded, and focused in class. Many discussed how beginning the class with a brief meditation facilitated a "clean slate for class to begin" and offered "that subtle shift that allowed me to be fully present," which helped students "be more focused and ready to listen." Participants discussed how "just the act of putting your phone down" to begin the meditations helped them focus. They also reported how MM helped them "be more present in class, rather than be distracted by outside factors," noting the importance of the meditations for bringing students into the present, "instead of stressing about future deadlines." Participants also discussed how the above theme of facilitating a sense of calm permitted them to be "more focused in class." To sum, one participant said, "I enjoyed the clarity, focus, and positivity it brought to my mind. It helped remove distractions and negative thoughts."

The idea of MM promoting student focus was also connected directly to learning through engagement with the class and course material. Participants noted how they were less distracted, with one saying, "I didn't find myself kind of drifting off to Facebook or Instagram or whatever." Others discussed how taking a brief moment "at the beginning of class definitely made the rest of the time higher quality learning." Participants often discussed how MM promoted a more engaging learning environment, with one summarizing how "it helped people be ready to um, engage fully in the class... as opposed to... 
just absentmindedly running through the motions. I think people were more engaged in the activities and we'd have better discussions in the class too." Participants felt that the MM facilitated the ability to "focus on present material" even beyond class time, saying, "I was able to increase recall of information from previous lectures, and readings for the course." Another participant said meditation facilitated "being able to control my thoughts... and get to a...mind space where I know that I know the material and I know that I can succeed," suggesting MM may relate to student engagement and ability to focus more broadly as well.

\section{Theme 3: MM Promotes Student Mental Health}

A further recurring theme in the focus groups and online survey responses was the connection between MM and student mental health. It is clear through our discussions with participants that students tend to have very busy schedules, face significant demands, and, as a result, experience feelings of stress and anxiety. Participants specifically discussed pressure relating to the transitions they were experiencing. One said, "I was transitioning from the workforce, back to school. It was very challenging for me," while another said, "I was very excited to start university, but also nervous to find it difficult to manage between my role as a mom of three and a student." They noted these challenges and stressors could be alleviated with MM, with one saying, "I began to use MM on my own to cope with stressful situations and the balance of home life, schoolwork, and my health." One summarized these feelings by saying, "Even if I felt overwhelmed...I knew that I would have the opportunity to meditate... That was very useful when I felt like school commitments had my head just floating above the water. Meditation acted as a life preserver that gave me the support I needed.” This statement clearly shows the importance of MM for this participant.

Participants directly connected MM to relieving stress and anxiety. One simply said, "I started doing mindfulness in class and realizing how much I can control, kind of, my anxiety levels." Others drew connections to transitions in their life, with one saying, "I graduated Grade 12 in June, so I was coming fresh into university...there's just like a lot of new things," and another saying that MM "alleviated transition stress because it was a familiar and relatable concept and practice for me, which in the midst of many unfamiliar practices and ways of thinking was comforting and grounding." Another 
participant said, "I learned to cope with anxiety, stress, and meditation is a way that works for me... It has completely shifted the way I think, and the positive results are visible, in my grades, personal relationships, and attitudes," connecting MM to mental health and overall student well-being.

Our participants also drew connections more broadly between MM and mental health promotion. One said, "Altering the classroom environment to provide coping mechanisms for stress creates a culture of resilience," while another said that "practising meditation in the classroom really normalizes good mental health practices." Another connected MM and mental health to her own experiences, saying, "I've been struggling with like anxiety and depression [so] just knowing I kind of had an outlet and a way to kind of control my thoughts." Other participants noted the value of this form of self-reflection, with one saying MM helped them to "pay attention to myself... what I am thinking right now and how I feel," and another suggesting the meditations offered a "time to reconnect with myself and reflect on how I was feeling." One connected this more directly to transitions, saying, "[MM] helped with these transitions as it gave me time to stop and reflect on my life choices and the new experiences," suggesting MM may ease stress associated with student transitions.

\section{Theme 4: MM Positively Changes Classroom Environment}

The final theme resulting from this work was how MM positively contributed to the overall classroom environment. Participants regularly discussed how MM facilitated a sense of connection and togetherness in the classroom. One said, for example, "It helped everyone feel closer and more connected," while another said, "that definitely makes a difference in how we all work together." Other participants suggested that MM "gave me a deeper connection with classmates... it was a great contribution to a collaborative learning environment," and "created an environment that embraced sharing ideas and being open." Others connected this directly to student transitions, saying, "It made me feel more optimistic about the [program] being a good fit for me...which made me feel more connected to instructors and classmates." This statement indicates how students value the sense of connection provided by MM.

Participants also discussed the value of a sense of closeness or togetherness. They commented on the value of everyone "starting from the same spot" and "sharing a few 
moments every class together." Notably, participants connected this to concepts of equality and inclusion, saying that MM "definitely levelled kind of the power divide in the classroom" and made for a "more inclusionary classroom." One participant said, "Meditation in the classroom made me feel as though everyone, including [the instructor], were starting class on the same page, and that made me feel more equal or less intimidated," suggesting MM may have value in creating a collaborative learning environment.

An important part of the impact MM had on the classroom environment was the impact it had on relationships in the course. In addition to the above-described sense of connection and collaboration, participants also discussed their relationships with one another as a result of MM. One said, for example, "I created some really good friends from that class. Umm, and anyone from that class that I see kind of walking on campus or whatever, like I'll stop to have a conversation with them." Another said, "I still feel comfortable when I see them in other classes. Like I can walk up to them and chat with them," suggesting the student connections extend beyond class as well. Notably, participants also discussed a positive impact on their relationship with the instructor. One said, "It did make me feel like my professor understood mental health issues," while another echoed that "it shows that the prof not only teaches health promotion but...cares about the promotion of health even in her classroom." Others noted they appreciated "knowing that someone cared about their students," with one saying that "it helped me feel that the professor truly cared about the well-being of her students."

\section{Challenges and Recommendations}

In addition to the benefits discussed above, participants also identified several challenges regarding incorporating $\mathrm{MM}$ in the classroom. The most commonly discussed challenge centred on the fact that because meditations occurred at the beginning of class, others sometimes arrived late during the meditation. One participant said, for example, "Students come in late and I find myself a bit distracted as well as self-conscious." Others pointed out that it could be challenging, especially in classes outside of related disciplines, to garner "buy-in," "commitment," or get "everybody onboard." One participant pointed out the challenge for instructors to incorporate MM if "it's not explicitly in your curriculum or programming." Other participants suggested that using MM beyond the classroom might be challenging for students who may "get frustrated... about not being 
good at it" or who may forget techniques learned or applied in class. Finally, one participant highlighted that MM “doesn't actually change the circumstances causing anxiety," though they did say it still "helps greatly in terms of coping and resilience."

Participants also shared with us their ideas and recommendations for incorporating MM into the class. Several participants made suggestions about meditation length, with some suggesting the need to "keep it short," while others suggested "it would be great [if] the time can be a little bit longer"; future research could explore ideal lengths of in-class guided meditations. Others made recommendations regarding comfortable spaces and lights that can dim. Some participants suggested faculty members in other courses and departments should explore incorporating the practice, with one saying, "I think that no matter what faculty, no matter what class you'll definitely see a positive outcome"; however, other participants suggested that if others were to incorporate MM it would also be important to "acknowledge where it comes from" and to explain the "kind of influence mediation can have on people." Finally, one participant suggested that adding workshops to introduce the concept to other courses might be helpful.

\section{Discussion}

The purpose of this study was to understand how students perceive using MM in an introductory health promotion course, and how this practice relates to transitions they may experience. Our findings align with findings from other studies about MM used in other educational contexts; however, they add to the literature as they are unique in that our findings connect the use of MM in the post-secondary classroom and transitions in post-secondary education. These topics have not previously been studied together and add to the literature regarding MM in educational contexts. Additionally, the findings add to the collection of research conducted through a post-structural lens.

The first theme identified was that the incorporation of MM into the classroom facilitated a sense of peace and calm among students. Many participants described inclass meditations as an opportunity to pause or slow down, particularly when they were feeling overwhelmed. These findings are similar to results from a study by Monshat and colleagues (2012) who found that the use of mindfulness allowed participants to approach their daily lives with a sense of calm and balance. In addition to facilitating a sense of 
peace and calm in the classroom, students also frequently discussed how MM assisted students in focusing, being less distracted, and feeling present and grounded during class. Hick and Bien (2008) discussed the term "reperceiving" as an end goal of mindfulness practice, which allows individuals to experience a shift in focus; it appears that this is what students were experiencing in class. Participants often connected their feelings about the use of MM directly to their ability to learn through engagement in the classroom environment and with course material. Similarly, Monshat and colleagues (2012) found that their participants perceived the practice of mindfulness to help them feel more confident and competent in their abilities.

Another theme in our findings was the connection between MM and student mental health. The connection between student mental health and mindfulness is a prominent finding in mindfulness research. Incorporating MM into higher education has been shown to promote student mental health (Waters et al., 2015). As mentioned, decreased levels of stress, anxiety, and depression have been found as benefits of using MM in the classroom (Kinsella et al., 2018; McConville et al., 2017; Schwind et al., 2017). Additionally, Lindsay and colleagues (2018) found that mindfulness training positively impacts resilience and life satisfaction and reduces negative thoughts. Participants discussed their busy schedules and significant demands, and their resultant feelings of stress and anxiety. They also discussed pressure relating to the transitions they were experiencing and noted these pressures could be alleviated with MM. Similar to this finding, Monshat and colleagues (2012) found that practising mindfulness helped participants with emotional regulation and with their confidence in handling life challenges. Participants also noted the value of this form of self-reflection, which is aligned with evidence that mindfulness promotes introspection, decentering, self-observing, and reflective functioning (Bishop et al., 2004).

The final theme identified through this research was how MM contributed to a positive classroom environment. This is aligned with previous evidence, in that Klatt and colleagues (2013) found that arts-based mindfulness in an elementary class positively impacted the classroom environment by reducing stress in the classroom. Additionally, Ramsburg and Youmans (2014) found that the use of meditation in a higher-learning classroom facilitated a positive learning environment. Our participants identified a sense of togetherness in the classroom as a result of MM, with some participants noting MM allowed for a deeper connection with their classmates. Further, our participants also discussed their relationships with one another as a result of MM. Similarly, Wisner and 
colleagues (2010) found that school-based use of MM helps facilitate a sense of community among students.

A key strength of this project is that we connected MM with transitions experienced by university students, an interesting and important research topic which has not been previously explored. Another strength of this project is that we were able to explore $\mathrm{MM}$ in the post-secondary classroom environment, contributing to an understudied and emerging area of research. A third major strength of this research is the participatory approach and use of student researchers as members of the research team. Two limitations also warrant discussion. First, students self-selected to participate, which may have caused a bias in the resulting data. Second, data were not collected until final grades were submitted, resulting in a period of time between participation in the course (and MM) and completion of the survey or interview, meaning students needed to rely on their recall of experiences.

Several opportunities exist for future research in this area. First, because this was a qualitative study with a small sample size, future studies might explore a larger sample of students using quantitative or mixed methods to gather a different outlook on this topic. Another opportunity for future study could include studying the direct connection between MM and students' academic outcomes in the context of transitions. Further research could explore the themes that were identified through this study. For example, this study determined that the use of MM positively changes the classroom environment. It would be interesting to understand what students perceive to be the aspects of the classroom environment that change as a result of the use of MM in more detail.

Students also identified several challenges regarding the incorporation of MM into the introductory health promotion classroom, which point to opportunities for both research and practice. The challenge most commonly identified was the fact that meditations done at the beginning of class posed challenges when students arrived late. As such, it would be interesting to research the process of incorporating MM into the classroom by analyzing meditation type, length, or setting, for example. The class in which we studied MM was a health promotion class in which most students were aware of their health and receptive to participating; however, the students who would benefit most from mindfulness training may not be enrolled in one specific program or motivated to engage in it (Rizer et al., 2016). In order to expose all students to the benefits of meditation, it is recommended that it be integrated into a core curriculum (Barbosa et al., 2013). This 
connects further to discourse around individual student responsibility, and points to opportunity for institutional change to support students more broadly. Since it is currently the independent responsibility of educators to include MM into their classrooms, future research could be reframed to encourage institutional change and student support. By legitimizing the practice and including it in the classroom, concerns of students' well-being and academic performance may be addressed (Napora, 2011).

\section{Conclusion}

Through this study we sought to understand student perceptions of the impacts of the use of MM in an introductory health promotion course, and how MM relates to student transitions. Key themes were identified from this research, along with challenges and recommendations. It was found that MM facilitates a sense of peace and calm and encourages student focus, helps promote student mental health, and positively changes the classroom environment. Future research in this area may explore these themes in further detail, may use different methods, or may explore factors influencing implementation of MM in post-secondary classrooms. 


\section{References}

Barbosa, P., Raymond, G., Zlotnick, C., Wilk, J., Toomey, R., III., \& Mitchell, J., III. (2013). Mindfulness-based stress reduction training is associated with greater empathy and reduced anxiety for graduate healthcare students. Education for Health, 26(1), 9-14. https://doi.org/10.4103/1357-6283.112794

Bishop, S. R., Lau, M., Shapiro, S., Carlson, L., Anderson, N. D., Carmody, J., Segal, Z. V., Abbey, S., Speca, M., Velting, D., \& Devins, G. (2004). Mindfulness: A proposed operational definition. Clinical Psychology: Science and Practice, 11(3), 230-241. https://doi-org.ezproxy.library.dal.ca/10.1093/clipsy.bph077

Bloch, J. H., Farrell, J. E., Hook, J. N., Van Tongeren, D. R., Penberthy, J. K., \& Davis, D. E. (2017). The effectiveness of a meditation course on mindfulness and meaning in life. Spirituality in Clinical Practice, 4(2), 100-112. https://doi. org/10.1037/scp0000119

Braun, V., \& Clarke, V. (2006). Using thematic analysis in psychology. Qualitative Research in Psychology, 3, 77-101.

Briggs, A., Clark, J., \& Hall, I. (2012). Building bridges: Understanding student transition to university. Quality in Higher Education, 18(1), 3-21. https://doi.org/10.1080/1 $\underline{3538322.2011 .614468}$

Cheek, J. (1999). Postmodern and poststructural approaches to nursing research. Sage.

Christie, H. Tett, L., Cree, V. E., \& McCune, V. (2016). "It all just clicked”: A longitudinal perspective on transitions within university. Studies in Higher Education, 41(3), 478-490. https://doi.org/10.1080/03075079.2014.942271

Coertjens, L., Brahm, T., Trautwein, C., \& Lindblom-Ylänne, S. (2017). Students’ transition into higher education from an international perspective. Higher Education, 73(3), 357-369. https://doi.org/10.1007/s10734-016-0092-y

Crowley, C., \& Munk, D. (2017). An examination of the impact of a college level meditation course on college student well-being. College Student Journal, 51(1), 91-98.

De Clercq, M., Roland, N., Brunelle, M., Galand, B., \& Frenay, M. (2018). The delicate balance to adjustment: A qualitative approach of student's transition to the first 
year at university. Psychologica Belgica, 58(1), 67-90. https://doi.org/10.5334/ pb.409

Gale, T., \& Parker, S. (2014). Navigating change: A typology of student transition in higher education. Studies in Higher Education, 39(5), 734-753. https://doi.org/10. $\underline{1080 / 03075079.2012 .721351}$

Gardner, P., \& Grose, J. (2015). Mindfulness in the academy-Transforming our work and ourselves "One Moment at a Time." Collected Essays on Learning and Teaching, 8, 35-46.

Gibson, S., Grace, A., O’Sullivan, C., \& Pritchard, C. (2018). Exploring transitions into the undergraduate university world using a student-centred framework. Teaching in Higher Education, 1-15. https://doi.org/10.1080/13562517.2018.1511538

Hick, S., \& Bien, T. (2008). Mindfulness and the therapeutic relationship. Guilford Press. Hussey, T., \& Smith, P. (2010). Transitions in higher education. Innovations in Education and Teaching International, 47(2), 155-164. https://doi. org/10.1080/14703291003718893

Janiga, S. J., \& Costenbader, V. (2002). The transition from high school to postsecondary education for students with learning disabilities: A survey of college service coordinators. Journal of Learning Disabilities, 35(5), 463-70. https://doi.org/10.1 $\underline{177 / 00222194020350050601}$

Jha, A. P., Krompinger, J., \& Baime, M. J. (2007). Mindfulness training modifies subsystems of attention. Cognitive, Affective, \& Behavioral Neuroscience, 7(2), 109-119. https://doi.org/10.3758/CABN.7.2.109

Kabat-Zinn, J., Massion, A. O., Kristeller, J., Peterson, L. G., Fletcher, K. E., Pbert, L., Lenderking, W. R., \& Santorelli, S. F. (1992). Effectiveness of a meditation-based stress reduction program in the treatment of anxiety disorders. American Journal of Psychiatry, 149(7), 936-943. https://doi.org/10.1176/ajp.149.7.936

Kinsella, E. A., Smith, K., Bhanji, S., Shepley, R., Modor, A., \& Bertrim, A. (2018). Mindfulness in allied health and social care professional education: A scoping review. Disability and Rehabilitation, 5(1), 1-13. https://doi.org/10.1080/0963828 $\underline{8.2018 .1496150}$ 
Klatt, M., Harpster, K., Browne, E., White, S., \& Case-Smith, J. (2013). Feasibility and preliminary outcomes for Move-Into-Learning: An arts-based mindfulness classroom intervention. The Journal of Positive Psychology, 8(3), 233-241. https://doi.org/10.1080/17439760.2013.779011

Laing, C., Robinson, A., \& Johnston, V. (2005). Managing the transition into higher education: An on-line spiral induction programme. Active Learning in Higher Education, 6(3), 243-255. https://doi.org/10.1177/1469787405059575

Leese, M. (2010). Bridging the gap: Supporting student transitions into higher education. Journal of Further and Higher Education, 34(2), 239-251. https://doi. org/10.1080/03098771003695494

Lindsay, E. K., Chin, B., Greco, C. M., Young, S., Brown, K. W., Wright, A. G. C., Smyth, J. M., Burkett, D., \& Creswell, J. D. (2018). How mindfulness training promotes positive emotions: Dismantling acceptance skills training in two randomized controlled trials. Journal of Personality and Social Psychology, 115(6), 944-973. https://doi.org/10.1037/pspa0000134

McConville, J., McAleer, R., \& Hahne, A. (2017). Mindfulness training for health profession students - The effect of mindfulness training on psychological well-being, learning and clinical performance of health professional students: A systematic review of randomized and non-randomized controlled trials. EXPLORE, 13(1), 26-45. https://doi.org/10.1016/j.explore.2016.10.002

McGhie, V. (2017). Entering university studies: Identifying enabling factors for a successful transition from school to university. Higher Education: The International Journal of Higher Education Research, 73(3), 407-422. https://doi. org/10.1007/s10734-016-0100-2

McInnis, C. (2010). Researching the first year experience: Where to from here? Higher Education Research \& Development, 20(2), 105-114. https://doi. org/10.1080/07294360125188

Meehan, C., \& Howells, K. (2018). In search of the feeling of 'belonging' in higher education: Undergraduate students transition into higher education. Journal of Further and Higher Education, 43(10), 1376-1390. https://doi.org/10.1080/03098 $\underline{77 X .2018 .1490702}$ 
Miles, M. B., \& Huberman, A. M. (1994). Qualitative Data Analysis: An expanded sourcebook (2nd ed.). Sage.

Miller, J. J., Fletcher, K., \& Kabat-Zinn, J. (1995). Three-year follow-up and clinical implications of a mindfulness meditation-based stress reduction intervention in the treatment of anxiety disorders. General Hospital Psychiatry, 17(3), 192-200. https://doi.org/10.1016/0163-8343(95)00025-M

Monshat, K., Khong, B., Hassed, C., Vella-Brodrick, D., Norrish, J., Burns, J., \& Herrman, H. (2012). "A conscious control over life and my emotions": Mindfulness practice and healthy young people. A qualitative study. Journal of Adolescent Health, 52(5), 572-577. https://doi.org/10.1016/j. jadohealth.2012.09.008

Napora, L. (2011). Meditation in higher education: The question of change, a current problem, and evidence toward a solution. Biofeedback, 39(2), 64-66. https://doi. org/10.5298/1081-5937-39.2.06

Ramsburg, J. T., \& Youmans, R. J. (2014). Meditation in the higher-education classroom: Meditation training improves student knowledge retention during lectures. Mindfulness, 5(4), 431-441. https://doi.org/10.1007/s12671-013-0199-5

Rizer, C. A., Fagan, M. H., Kilmon, C., \& Rath, L. (2016). The role of perceived stress and health beliefs on college students' intentions to practice mindfulness meditation. American Journal of Health Education, 47(1), 24-31. https://doi.org/0 $\underline{.1080 / 19325037.2015 .1111176}$

Schwind, J. K., McCay, E., Beanlands, H., Martin, L. S., Martin, J., \& Binder, M. (2017). Mindfulness practice as a teaching-learning strategy in higher education: A qualitative exploratory pilot study. Nurse Education Today, 50(4), 92-96. https:// doi.org/10.1016/j.nedt.2016.12.017

Shapiro, S. L., Brown, K. W., \& Astin, J. A. (2008). Toward the integration of meditation into higher education: A review of research. http://www.contemplativemind.org/ admin/wp-content/uploads/2012/09/MedandHigherEd.pdf

Stone, D. (2010). High to low tide: The high school-university transition. Collected Essays on Learning and Teaching, 3, 133-139. https://doi.org/10.22329/celt. v3i0.3252 
Valentine, E. R., \& Sweet, P. L. G. (1999). Meditation and attention: A comparison of the effects of concentrative and mindfulness meditation on sustained attention. Mental Health, Religion \& Culture, 2(1), 59-70. https://doi. org/10.1080/13674679908406332

van Herpen, S., Meeuwisse, M., Hofman, W., \& Severiens, S. (2019). A head start in higher education: The effect of a transition intervention on interaction, sense of belonging, and academic performance. Studies in Higher Education, 45(4), 862-877. https://doi.org/10.1080/03075079.2019.1572088

Waters, L., Barsky, A., Ridd, A., \& Allen, K. (2015). Contemplative education: A systematic, evidence-based review of the effect of meditation interventions in schools. Educational Psychology Review, 27(1), 103-134. https://doi.org/10.1007/ s10648-014-9258-2

Wisner, B. L., Jones, B., \& Gwin, D. (2010). School-based meditation practices for adolescents: A resource for strengthening self-regulation, emotional coping, and self-esteem. Children \& Schools, 32(3), 150-159. https://doi.org/10.1093/ cs/32.3.150 